Review Article

\title{
Surface-Initiated Ring-Opening Metathesis Polymerization (SI- ROMP): History, General Features, and Applications in Surface Engineering with Polymer Brushes
}

\author{
Qingchuan Chen \\ Shenzhen College of International Education, Shenzhen, Guangdong Province 518043, China \\ Correspondence should be addressed to Qingchuan Chen; s16231.chen@stu.scie.com.cn
}

Received 6 December 2020; Revised 6 January 2021; Accepted 24 January 2021; Published 9 February 2021

Academic Editor: Mehdi Salami-Kalajahi

Copyright (C) 2021 Qingchuan Chen. This is an open access article distributed under the Creative Commons Attribution License, which permits unrestricted use, distribution, and reproduction in any medium, provided the original work is properly cited.

\begin{abstract}
Surface-Initiated Ring-Opening Metathesis Polymerization (SI-ROMP) has attracted great attention in the past two decades because of its high efficiency in decorating material surfaces with functional polymer brushes. To fill the vacancy of review articles in SI-ROMP, this article is aimed at giving an overview of the history, the general features and procedures, and applications of SI-ROMP, guiding future researchers in this field. In general, SI-ROMP consists of three main steps: surface functionalization with olefin anchors, attachment of catalyst to the surface, and polymerization from the surface. Several metalbased catalysts for ROMP in solution have been developed, but most SI-ROMP reactions use the ruthenium-based Grubbs catalysts. SI-ROMP enables the rapid growth of polymer films on a large variety of substrates such as silica, gold, graphene oxides, carbon nanotubes, metal oxide nanowires, and composite polymer membranes. There are many methods to characterize these polymer brushes. In addition, some novel techniques have been developed to precisely control the surface polymer growth and lead to polymer films with unique structures and functions. Up to this day, SI-ROMP can be applied to the surface engineering of many novel materials, including ultrahydrophobic surfaces, microfluidic channels, electric devices, ion exchange media, and responsive surfaces.
\end{abstract}

\section{Introduction}

With its first report in the mid-1950s [1], Ring-Opening Metathesis Polymerization (ROMP) of olefins has been investigated and researched for decades. After the development of well-defined metal catalysts, ROMP has become a robust polymerization method that has high efficiency and broad applicability to different functional groups [2-7]. It has been used to synthesize functional polymers with applications in various fields, including biomedicine [8], lithium-ion batteries [9], and photonic crystals [10]. Although there are extensive researches of ROMP in solution, ROMP at the surface is a comparatively new concept. One of the earliest reports of such reactions was done by Weck et al. in 1999, where a norbornene derivative was polymerized on a gold surface [11].
In general, two methods were commonly adopted to generate polymer films on surfaces: "grafting-to" and "graftingfrom" (Figure 1). In a grafting-to approach, presynthesized polymer molecules are attached to a functionalized substrate, while in a grafting-from approach, polymer chains grow from the functionalized surface on the addition of monomers. Although the grafting-to approach is more straightforward in terms of experiments, the grafting-from approach is also favored due to its ability to generate polymer films with high densities and thicknesses [12]. A commonly adopted name used to refer to the grafting-from approach is Surface-Initiated Polymerization (SIP). This type of reaction enables polymer films of different compositions and architectures, with different properties and applications, to be covalently anchored on a large variety of substrates. 


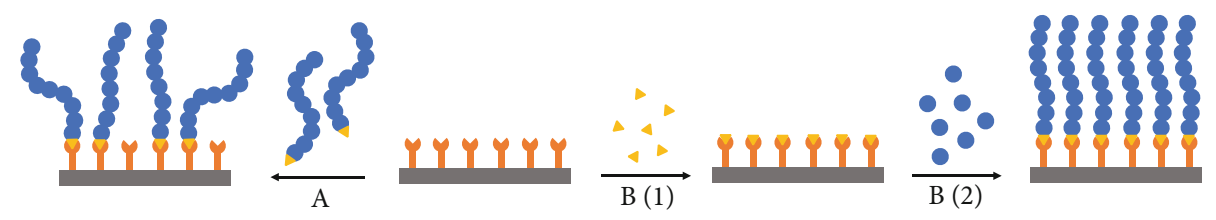

Figure 1: The (A) grafting-to and (B) grafting-from approaches to generate polymer films on surfaces. For (B), (1): initiator/catalyst attachment to surface, and (2): polymerization from the surface.

To this day, many types of SIP reactions have been developed, such as Surface-Initiated Controlled Radical Polymerization (SI-CRP) [12] and surface-initiated cationic or anionic polymerizations [13]. However, the Surface-Initiated ROMP technique, in particular, has attracted quite some attention in the past two decades [11, 14-48]. Although there exist several review articles in either the field of ROMP reactions $[1,4,49-51]$ in general or in other types of SIP reactions $[12,13]$, to the best of my knowledge, there still lacks a comprehensive review on Surface-Initiated Ring-Opening Metathesis Polymerization (SI-ROMP).

This review is aimed at giving an overview of the general features and recent advances on SI-ROMP, providing an introductory guide for future researchers in this field. The reaction mechanism, the catalyst, the kinetics of film growth, the factors controlling film thickness, and the general procedures of SI-ROMP reactions are first introduced. The methods to characterize the polymer brushes will be mentioned. In addition, the strategies to conduct SI-ROMP on different substrates, special techniques to control SI-ROMP reactions, and the applications of the surface-tethered polymer brushes will be discussed.

\section{Mechanism and Catalysts of ROMP}

In 1971, Chauvin proposed a mechanism for the olefin metathesis reactions catalyzed by a metal carbene (alkylidene) complex [52], which is widely agreed today as the actual mechanism taking place in olefin metathesis. The most crucial steps involves a $[2+2]$ cycloaddition reaction between the $\mathrm{C}=\mathrm{C}$ bond of the olefin and the $\mathrm{M}=\mathrm{C}$ bond of the metal alkylidene complex, giving a four-membered ring referred to as a metallacyclobutane, which then undergoes a cycloreversion reaction to generate the olefin metathesis products.

Cyclic olefins can also react through this mechanism. Due to the presence of the ring structure in the olefin, after the cycloreversion step, the olefin remains connected to the metal, as an extension to the alkylidene ligand. This new alkylidene can then continuously react with other cyclic olefin molecules, resulting in ROMP (Scheme 1). It has been noted that the driving force of ROMP reactions for cyclic monomers is the release of the ring strain of the cyclic monomers. For relatively small-ring cyclic olefins, the ringopening procedure would release their large strain energies, and hence, the ROMP is more exothermic and thermodynamically favorable. It was reported by Lerum and Chen that the degree of polymerization of a ROMP polymer chain is positively related to the strain energy of the monomer under certain conditions [18].
The Chauvin mechanism pushed the development of single-component well-defined metal-alkylidene and metallacyclobutane catalysts for olefin metathesis in the 1980 s [53]. One of the very first reports is a tungsten carbene complex, first prepared by Casey and Fischer [54-58], but its catalytic activity towards ROMP was reported by Katz et al. in 1976 [59, 60]. Later, various metal-alkylidene complexes have also been reported to catalyze ROMP reactions [61, 62], with the metal centers being molybdenum, tungsten, titanium, or tantalum [63-67]. At the same time, researchers were also focusing on improving the functional group selectivity of the catalysts. It was discovered that the catalysts had better selectivity towards olefins when the metal centers were varied from left to right and from bottom to top on the periodic table [68]. Following this trend, ruthenium complexes should exhibit both high reactivities with carboncarbon double bonds and extraordinary stability towards other functional groups [53].

Grubbs et al. reported the first ruthenium alkylidene complex synthesized from $\mathrm{RuCl}_{2}\left(\mathrm{PPh}_{3}\right)_{2}$ and 3,3-diphenylcyclopropene that exhibited catalytic activity towards ROMP in 1992 [69]. In 1995, the Grubbs 1st generation catalyst (Figure 2(a)) was developed [70, 71]. Since then, the Grubbs 2nd generation (Figure 2(b)) and the 3rd generation catalysts [72] (Figure 2(c)) were synthesized, with the catalytic activity increasing substantially from generation to generation. These catalysts are used widely in labs or industrially today in ROMP due to their high stability, reactivity, and functional group tolerance. The SI-ROMP researches investigated in this review have mostly used Grubbs catalysts [11, 14-48], although the work of Buchmeiser et al. mentioned that the Schrock type catalysts could also be used for SI-ROMP reactions [27].

Overall, ROMP proceeds through the well-known Chauvin mechanism of olefin metathesis, involving repeated $[2+$ 2]-cycloaddition and cycloreversion steps between the cyclic olefin monomer and the reactive center of the metal alkylidene. Although many catalysts for olefin metathesis have been developed, practically all SI-ROMP researches used the Grubbs catalysts.

\section{Surface-Initiated ROMP (SI-ROMP)}

As a surface-initiated variant of ROMP, the fundamental polymerization mechanism of SI-ROMP is essentially similar to that of ROMP. However, instead of allowing the catalyst and the olefin monomers to mix thoroughly and react in solution, the polymerization in SI-ROMP is confined to the surface of the substrate. Hence, compared to the solutionphase ROMP, SI-ROMP has some unique features in terms 


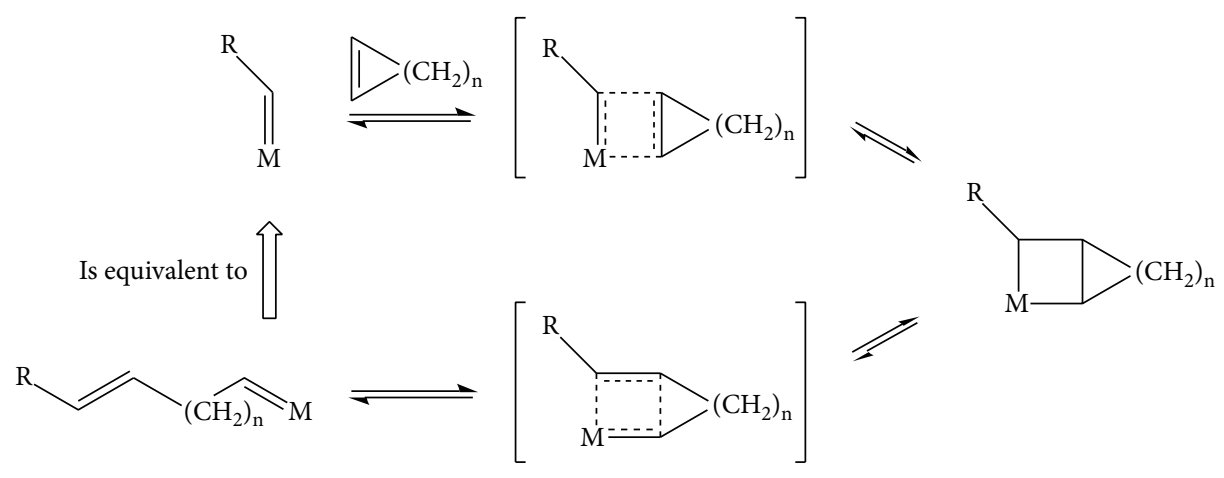

Scheme 1: Mechanism for Ring-Opening Metathesis Polymerization of cyclic olefins.

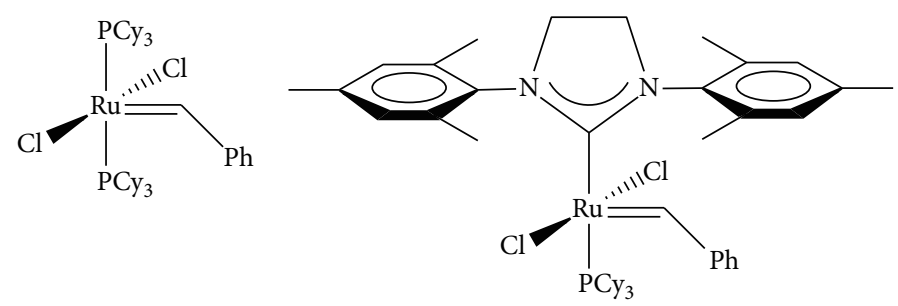

(a)

(b)

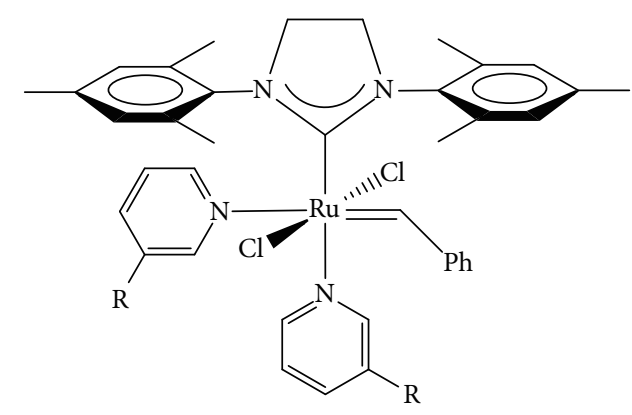

$\mathrm{R}=\mathrm{H}$ or $\mathrm{Br}$

(c)

Figure 2: The Grubbs (a) first generation, (b) second generation, and (c) third generation catalysts.

of experimental procedures, kinetics of the polymer growth, and side-reactions, which will be discussed in this section.

In general, SI-ROMP is performed by carrying out the following procedures (as depicted in Scheme 2) [11, 14-48]:

(1) Surface functionalization with olefin anchors. The olefin molecule should have a substrate-specific functional group that can attach to the substrate. For instance, chlorosilanes are used for silica surfaces and thiols are used for gold surfaces. At the other end of the attached molecule, the olefin group is used for the catalyst anchoring in the next step

(2) Attachment of catalyst to the surface. A ROMP catalyst is applied to the substrate. They react with the olefin groups on the surface and are thus covalently anchored to the substrate

(3) Polymerization from the surface. Monomers are supplied to the catalyst-activated surface and polymerize through the ROMP mechanism. The polymer chain grows from the surface, and the catalyst is constantly kept at the top of the polymer chain. Since the polymerization is initiated at the surface, the whole process is known as Surface-Initiated Ring-Opening Metathesis Polymerization (SI-ROMP). In the end, lots of polymer chains are covalently attached to the surface, generating a polymer film covering the entire surface

According to the pioneering work by Harada et al., the SIROMP reaction can be depicted by a series of coupled polymerization and termination reactions (Scheme 3) [33]. Assuming that for every step of polymerization (with the reaction rate constant being $k_{\mathrm{p}}$ ) there also exists a competing termination reaction (with the reaction rate constant being $k_{\mathrm{t}}$ ), they derived an expression for the thickness of the surfacegrafted polymer film with respect to time [33]:

$$
d=\left(\frac{k_{\mathrm{p}} M}{k_{\mathrm{t}}}\right)\left(\frac{m_{0} P_{\mathrm{I}}}{\rho}\right)\left(1-e^{-k_{\mathrm{t}} t}\right) .
$$




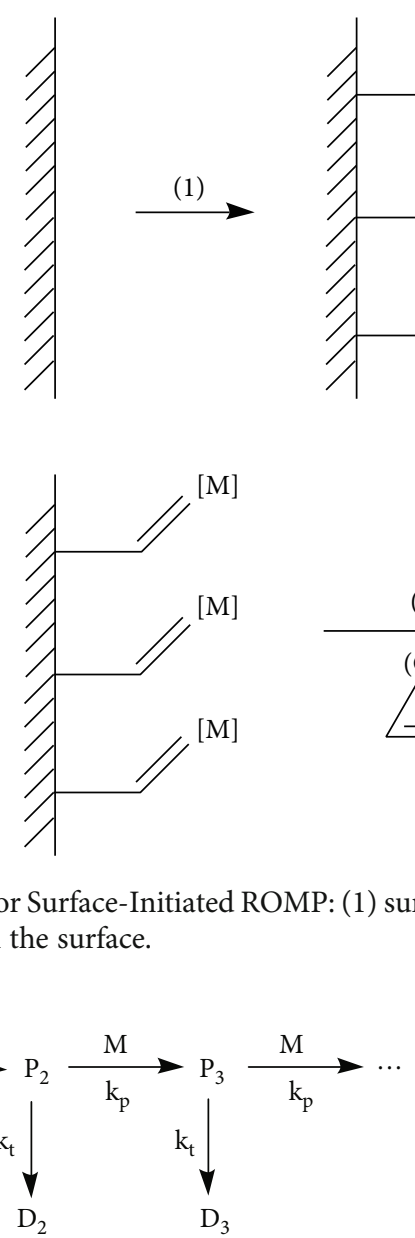

Scheme 3: The step-growth polymerizations and the competing termination reactions. Reprinted with permission from [33]. Copyright (c) 2003 American Chemical Society.

In Equation (1), the variables refer to the following: $d$ for the film thickness, $M$ for the monomer concentration, $m_{0}$ for the mass of the monomer unit, $P_{\mathrm{I}}$ for the initial number of active sites for polymer growth per unit area, $\rho$ for the density of the polymer film, and $t$ for the time since the polymerization has started. As shown in Figure 3(a), the experimental data are well fitted with Equation (1), where the thickness of the polymer film first grows rapidly, then gradually slows down until it approaches a horizontal asymptote as the maximum thickness is reached due to the irreversible terminations of the growing polymer chains [33]. In addition, it is also shown in Figure 3(a) that increasing the concentration of monomer $(M)$ can produce a thicker polymer film.

Berron et al. investigated the effect of the length of the side-chain on norbornene monomers on the thickness of the polymer film [19]. The experimental data and the fitted curves are shown in Figure 3(b), where pNB refers to polynorbornene with no side-chains, and $\mathrm{pCnNB}$ refers to polynorbornene with alkyl side-chains of length $n$. According to their results, they concluded that increasing lengths of sidechains on norbornene monomers generally reduced the reaction rate due to increasing steric hindrances, resulting in lower maximum thicknesses of film growth. The steric effect also reduced termination rates $k_{\mathrm{t}}$, as indicated by the reduction in the speed in which the thickness approached its maximum for the $\mathrm{pCnNB}$ films compared to the $\mathrm{pNB}$ film. The morphology of the grafted polymer films was investigated with AFM (Atomic Force Microscopy). As shown in Figure 4, dense polymer coatings were generated for $\mathrm{pNB}$, $\mathrm{pC} 4 \mathrm{NB}$, and $\mathrm{pC} 6 \mathrm{NB}$, while the polymerization of $\mathrm{C} 10 \mathrm{NB}$ only resulted in isolated islands.

Equation (1) also suggests that the thickness will increase by raising $P_{\mathrm{I}}$, by distributing active initiation sites more densely on the substrate. An example of this is by using macroinitiators with a substantially increased initiator density to vastly elevate the film thickness $[15,73]$, as shown in Figure 3(c). In 2013, Escobar et al. reported the combination of SI-ROMP with Surface-Initiated Atom-Transfer Radical Polymerization (SI-ATRP), to generate a polynorbornene film with an exceptional thickness (up to $1 \mu \mathrm{m}$ ) using macroinitiation. According to their research, they first carried out an SI-ATRP reaction to generate PHEMA (poly(2-hydroxyl methacrylate)) brushes on the surface, which then reacted with norbornene carbonyl chloride. The resulting norbornene-rich polymer was called a macroinitiator and can undergo SI-ROMP through the conventional procedures, generating much thicker polymer films compared to small molecule initiators.

During ROMP, there exist side-reactions such as the intermolecular and intramolecular chain transfer reactions which compete with the forward and desired polymerization reaction $[1,16,18]$. Intermolecular chain transfer is the cycloaddition-cycloreversion reaction of the reactive metal alkylidene center at the end of a growing polymer chain with an existing olefin group on the backbone of another polymer chain. This process cuts and swaps polymer segments and 


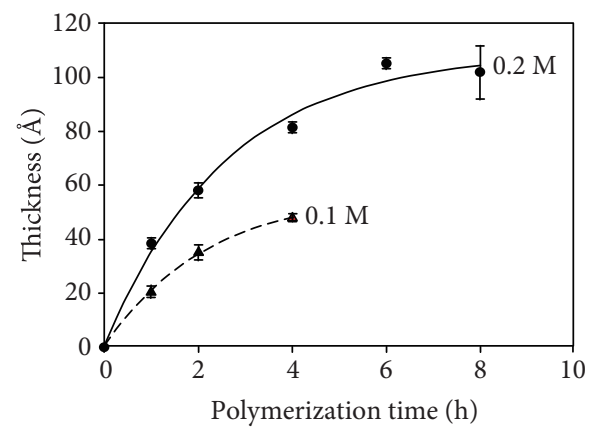

(a)

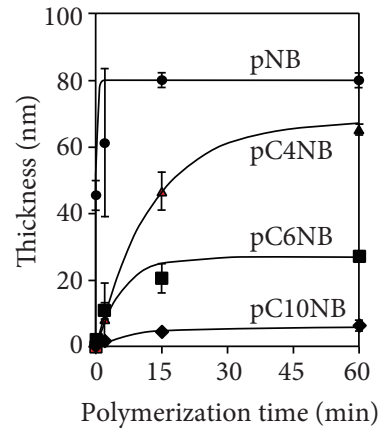

(b)

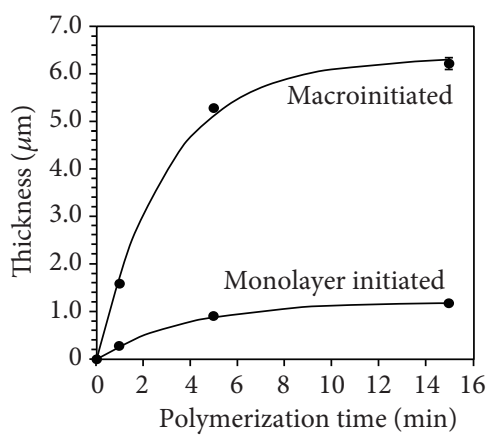

(c)

FIgURe 3: Thicknesses of polymer films recorded as functions of time, (a) with different monomer concentrations, reported in the work of Harada et al. [33]; (b) using monomers with different side-chain lengths, reported in the work of Berron et al. [19]; and (c) with different densities of active initiation sites (with or without using a macroinitiator) in the work of Escobar et al. [15]. Figures adapted with permissions from [15, 19, 33]. Copyright (c) 2003, 2007, 2013 American Chemical Society, respectively.
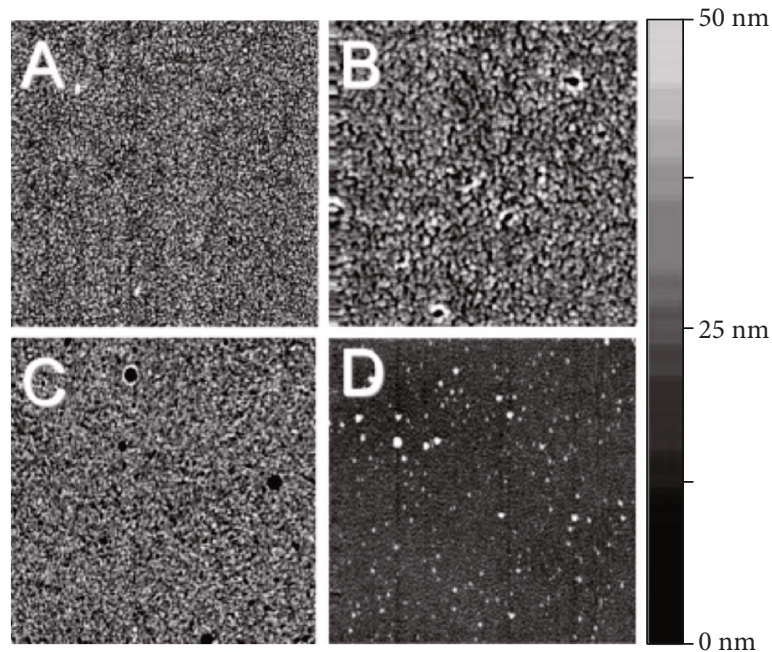

Figure 4: The AFM images $(25 \mu \mathrm{m} \times 25 \mu \mathrm{m})$ of (a) pNB, (b) pC4NB, (c) pC6NB, and (d) pC10NB. Figure reprinted with permission from [19]. Copyright (C) 2007 American Chemical Society.

metal centers between two polymer chains, varying the individual molecular weights even though the total number of polymer chains on the surface is conserved. Intramolecular chain transfer (referred to as "back-biting") involves the metal center bending back and reacting with an olefin on the same polymer strand, closing a loop to form a free cyclic oligomer that leaves the surface. After that, a polymer chain with a reduced molecular weight remains on the surface. Therefore, the intramolecular chain transfer decreases the polymer thickness on the surface. During the polymerization of a rigid cyclic olefin, like norbornene, the large thermodynamic favorability of the desired ring-opening polymerization weakens the effect of side-reactions. However, for the ROMP of low strain energy cyclic olefins like cyclooctane, where the driving force is weaker, the effect of the sidereactions can be significantly large [18].

Another side-reaction that deserves attention is the horizontal polymerization between adjacent olefin anchor molecules, competing with the desired perpendicular polymer chain growth. To weaken this effect, anchoring molecules without olefin groups can be used as spacers to control the density of olefin anchoring sites on the surface attached to the gold surface [11]. This method effectively generates loosely distributed catalyst anchoring sites on the substrate and hence prevents the undesired horizontal polymerizations.

To conclude, SI-ROMP consists of simply three steps: (1) surface functionalization with olefin anchors, (2) attachment of catalyst to the surface, and (3) polymerization from the surface. When the polymerization is modeled as a series of coupled polymerization and termination steps, a kinetic equation depicting thickness changes over time can be derived, and past researches have shown the effect of monomer concentrations, monomer side-chain lengths, and initiation site density, on the film thickness. The main side- 
reactions are the intermolecular and intramolecular chaintransfer reactions and horizontal polymerization between olefin anchors.

\section{Substrates and Olefin Anchor Design}

This section is aimed at discussing the substrates used for SIROMP and summarizing the previously reported substratespecific functional groups on the olefin anchor for attaching this molecule to the surface of the substrate, providing a guide for future researches on different substrates for conducing the "surface functionalization with olefin anchor" step of SI-ROMP.

To begin with, gold $(\mathrm{Au})$ substrates are one of the most common substrates for SI-ROMP. As gold possesses a high affinity towards sulfur, thiols (R-SH) with olefin groups are usually used to functionalize the surface. It is generally believed that a strong covalent thiolate bond, rather than a coordinative bond, is formed between the sulfur and gold. During the formation of the Au-S bond, the thiol group first deprotonates to a thiyl radical, which covalently bonds with the gold atom. In contrast, a nondeprotonated thiol group could only weakly interact with the gold atoms through coordination of the lone pairs on sulfur onto the empty orbitals on gold [74]. The attachment of olefin groups can also be done in a two-step manner, where the thiol molecules with hydroxyl groups (for instance, 4-mercapto-1-butanol) first react with the surface. Then, the hydroxyl-covered gold is reacted with an electrophile containing the olefin anchor, such as norbornenyl dicarbonyl chloride, to attach the olefin anchors onto the surface through condensation with the hydroxyl groups $[16,25,26]$. This method avoids the synthesis of the thiol-modified norbornene as the anchor molecule.

Silica $\left(\mathrm{SiO}_{2}\right)$ surfaces $[18,29]$ are also quite frequently used in SI-ROMP. Before the functionalization, silica surfaces are usually cleaned by the Piranha solution $[18,29$, 33 ], which generates exposed hydroxyl groups on the surface. Trichlorosilanes $\left(\mathrm{RSiCl}_{3}\right)$ [29, 30] and trialkoxysilanes $\left(\mathrm{RSi}(\mathrm{OR})_{3}\right)[75,76]$ with olefin groups are often used to react with these hydroxyl groups and so functionalize the surface. It was reported that the trichlorosilanes and trialkoxysilanes were first hydrolyzed to give trihydroxylsilanes $\left(\mathrm{R}-\mathrm{Si}(\mathrm{OH})_{3}\right)$ $[75,77-79]$, which then underwent condensation reactions with the hydroxyl moieties on the surface as depicted in Scheme 4. The remaining free hydroxyl groups on the silane molecule can participate in further condensations with the hydroxyl groups on either the silica surface or an adjacent silane, holding the attached olefin molecules onto the surface even more tightly. Furthermore, it is worth mentioning that the same strategies were used to perform SI-ROMP on silica nanoparticles $[47,75]$, which was used to improve the dispersion of these nanoparticles in polymer matrices (for instance, polyethylene and polynorbornene).

For crystalline silicon ( $\mathrm{Si}$ ) substrates, the exposed silicon-hydrogen $(\mathrm{Si}-\mathrm{H})$ bond can be used to attach olefin molecules to the surface [80]. Juang et al. first used a chlorinating agent $\left(\mathrm{PCl}_{5}\right)$ to convert $\mathrm{Si}-\mathrm{H}$ bonds to $\mathrm{Si}-\mathrm{Cl}$ bonds, which can then undergo nucleophilic substitution reaction with a Grignard reagent containing an olefin

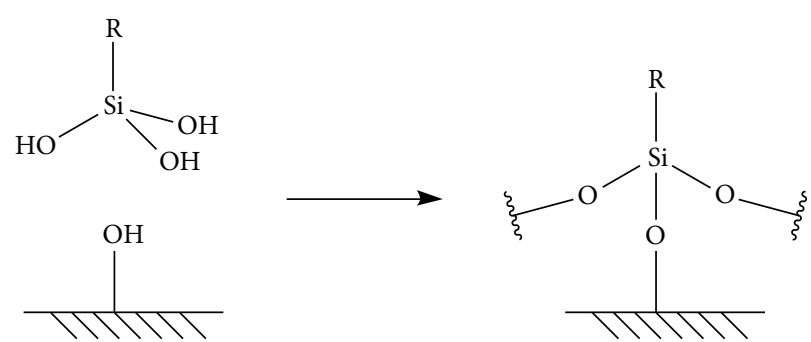

Scheme 4: Condensation reaction which attaches the hydroxysilanes to the silica surface.

group, such as $\mathrm{H}_{2} \mathrm{C}=\mathrm{CH}_{2} \mathrm{CH}_{2} \mathrm{MgBr}$, attaching the olefin anchor onto the surface.

Aside from gold, silica, and silicon, there are a variety of suitable substrates for SI-ROMP. For instance, Yan et al. reported SI-ROMP of norbornenes on titanium (IV) oxide nanowires [81]. Their anchoring molecule is shown in Figure 5(a), which contains a catechol (ortho-dihydroxybenzene) group, that is found to bind coordinatively onto the surface of titanium dioxide [82, 83]. SI-ROMP was also reported to be performed on cellulose fibers [24], graphene oxide [23], and carbon paper electrodes [25]. The similarity shared by the SI-ROMP on these three substrates is the shared use of an electrophilic norbornene carbonyl chloride (Figures 5(b) and 5(c)) as the anchoring molecule, targeting the hydroxyl moieties on the surfaces of the substrates. Pristine cellulose fibers have hydroxyl groups on the surface, while for graphene and carbon paper electrodes, an oxidation reaction, for instance, by exposing the carbon paper sample to $\mathrm{O}_{2}$ plasma, is required to generate the hydroxyl groups.

Noncovalent interactions have also been used to anchor the ROMP catalyst on the substrate. In the work of Gómez et al., where the performance of SI-ROMP on carbon nanotubes was described, the conventional method of first attaching an olefin anchor unit and then reacting the activated surface with the ROMP catalyst is not adopted. Instead, they used a catalyst with a pyrene group (Figure 6(a)), which can attach to the carbon nanotube through $\pi-\pi$ stacking, so the catalyst can be directly attached to the substrate without previously attaching an olefin anchor unit, simplifying the experimental process [84]. Attaching olefin anchors through electrostatic interaction is also reported by Kalluru and Cochran [32]. They conducted SI-ROMP of cyclopentene on montmorillonite clay (MMT), which consists of nanometer-sized sheets of negatively charged silicate material with cationic species floating between the gaps of the silicate sheets. To anchor olefin groups on MMT, a positively charged norbornene-quaternary ammonium molecule (Figure 6(b)) was used to replace the cations and to be attracted onto the sheets. After the SI-ROMP, the polymer brushes can be removed by ion exchange and characterized by gel permeation chromatography (GPC).

Furthermore, it was reported that electrografting technology could be utilized in the attachment of olefin anchors to the substrate $[17,85]$. The target substrate is used as the electrode, and the anchor molecules are reductively or oxidatively polymerized at the electrode surface to form a thin polymer film. In the work of Detrembleur et al. [85], acrylates 
<smiles>O=C(Cl)C1CC2C=CC1C2C(=O)NCCc1ccc(O)c(O)c1</smiles>

(a)<smiles>O=C(Cl)C1C2C=CC(C2)C1C(=O)Cl</smiles>

(c)

FIGURE 5: The (a) catechol norbornene, (b) norbornene carbonyl chloride, and (c) norbornene dicarbonyl chloride anchor molecules.<smiles>CCCC(C)(Cl)Cc1ccc(NC(=O)CCCc2ccc3ccc4cccc5ccc2c3c45)cc1</smiles>

(a)<smiles>CCOC(=O)C1C2C=CC(C2)C1C(=O)OC(C)(C)N(C)C(C)OC</smiles>

(b)

FIGURE 6: The (a) pyrene catalyst used in the SI-ROMP on carbon nanotubes and (b) the norbornene-quaternary ammonium anchor.

containing norbornene groups were put into contact with a conductive steel cathode, which is supplied with a voltage to reduce the acrylates, forming an invisible poly(norbornenylmethylene acrylate) layer across the electrode. Then, SIROMP proceeds through regular procedures. Later, Jiang et al. adopted a similar electrografting strategy on the anode [17]. They used thiophene-based anchoring molecules, with dendrons extending outwards with olefin groups at the tip. After applying a voltage over the electrodes, the thiophene molecules polymerize to a polythiophene film with olefin groups in the side chains.

In summary, previous work has demonstrated the broad applicability of SI-ROMP towards different substrates such as gold, MMT, cellulose fibers, and carbon nanotubes, ranging from inorganic to organic materials. The key is to choose an appropriate anchoring molecule for each substrate. Mainly, covalent bonds, coordinative bonds, $\pi-\pi$ interactions, and ionic interactions are used to anchor the olefin groups to the substrate for the immobilization of the catalyst, providing initiation sites of polymer chain growth.

\section{Characterization}

Accompanying the development of the SI-ROMP technique, various methods have been used to characterize the polymer films grafted on the surface. In general, two aspects of the surface-grafted polymer films attract the most attention: chemical structures and compositions, and film thickness and morphology. These properties are usually analyzed by infrared (IR) spectroscopy, X-ray photoelectron spectroscopy (XPS), ellipsometry, microscopy techniques, and contact angle. This section is aimed at introducing these most commonly used characterization methods in SI-ROMP and giving examples for the analysis of the obtained data.

5.1. Chemical Structures and Compositions. The chemical structures and compositions of the polymer film could be identified by a variety of analytical techniques. For instance, infrared (IR) spectroscopies such as Reflectance-Absorption IR Spectroscopy (RAIRS) and Transmission IR Spectroscopy are commonly used in SI-ROMP researches [15, 16, 19]. They could give characteristic peaks representing specific structures to match those of the monomer units, ascertaining polymer grafting. In the IR analysis of surface-tethered polynorbornene, researchers observed the expected peaks resembling the structures and functionalities of the polynorbornene film, including the peaks of cyclic methylene $\mathrm{C}-\mathrm{H}$ stretching, tertiary $\mathrm{C}-\mathrm{H}$ stretching, and $\mathrm{C}=\mathrm{CH}$ out-ofplane bending and stretching $[19,35]$. IR is also suitable for polymers containing unique functional groups, such as the $\mathrm{C}-\mathrm{F}$ bond in polyfluoronorbornenes $[21,25]$ and the carbonyl groups on poly(oxanorbornene-succinimide) [29]. X- 
ray Photoelectronic Spectroscopy (XPS) is used in determining the elemental compositions and structures of the topmost several nanometers of the polymer films [18, 21, 22, 29]. For example, Escobar et al. used XPS to verify the successful anchoring of the Grubbs 2nd generation catalyst by detecting the $\mathrm{Ru} 3 \mathrm{p}_{3 / 2}(462 \mathrm{eV})$ and $\mathrm{N} 1 \mathrm{~s}(400 \mathrm{eV})$ peaks [15]. To confirm a good coverage of the polymer film, one could observe the attenuation of XPS signals from the substrate. For instance, the disappearance of silicon peaks is usually observed after the surface-initiated polymerization on the silica surface $[39,86]$.

5.2. Film Thickness and Morphology. Ellipsometry is conducted routinely in SI-ROMP in order to characterize the thicknesses of surface-grafted polymer films [20, 22, 29], and their results have been used in analyses on film growth kinetics and factors affecting film thicknesses, as discussed earlier in the film grafting kinetics section of this article (Figures 3(a)-3(c)). Researchers were also interested in the morphology of surface-tethered polymer films, especially its coverage and roughness. Microscopy techniques are often used to obtain these pieces of information, such as Atomic Force Microscopy (AFM), Scanning Electron Microscopy (SEM), and Transmission Electron Microscopy (TEM) [11, $30,33,35]$. Their results provide a direct and intuitive image of the microscopic morphology of the surface. For instance, the growth of the polymer film has been monitored under AFM (Atomic Force Microscopy) to observe the surface morphology at different times of polymerization (Figure 7) [33]. As the polymerization progressed, Harada et al. observed a shift in film morphology from a reticulated pattern consisting of a branched network of polymer chains and "islands" to a more highly interconnected network with circular "holes," which were further filled in to give a more uniformly coated surface.

5.3. Contact Angles. Contact angles (goniometry) measure the affinities of polymer-grafted surfaces towards solvents with different polarities, such as water, hexacyclodecane, or diiodomethane [18-20]. Generally speaking, smaller advancing contact angles $\left(\theta_{\mathrm{A}}\right)$ mean that the surface has more affinity towards the chosen liquid, while larger advancing contact angles indicate a lower affinity towards the liquid due to polarity differences. For instance, the hydrophobic polynorbornene films demonstrate large and obtuse advancing contact angles with the polar liquid water, but small angles with the nonpolar liquid hexadecane $[15,19,25]$.

\section{Techniques for Performing SI-ROMP}

One reason why SI-ROMP has such a wide range of applications is its large flexibility. The procedures of SI-ROMP are comparatively simple, and the catalysts are highly selective. Hence, many special techniques could be employed in SIROMP in order to achieve a better control over the morphology, composition, and patterns of the polymer films without affecting the polymerization. This section will introduce some recently reported examples of such techniques.
6.1. Soft Lithography. Soft lithography methods were adopted by several researchers to generate polymer films with horizontal patterns, which have applications in microelectronic and MEMS (Microelectromechanical System) devices [29]. One of the common methods of soft lithography is Microcontact Printing $(\mu \mathrm{CP})[29,30,33]$. It is done by creating a stamp with the desired pattern, covering it with a layer of olefin anchor (referred to as "ink"), and then bringing the stamp into contact with the substrate to transfer the pattern [87]. Kim et al. demonstrated the high specificity of SI-ROMP towards regions functionalized with olefin anchors by noting that the resolution of the polymer patterns solely depended on the precision of the $\mu \mathrm{CP}$. Another soft lithography method reported in previous researches was Micromolding Surface-Initiated Polymerization ( $\mu$ MSIP) [73, 88]. First, a mold carrying the inverse height pattern of a master template is covered with a layer of catalyst and then filled with monomers and is pressed onto the olefin-activated substrate. Polymer growth is limited within the spaces of the dented-in regions (valleys) of the mold, generating patterned polymer "hills," "pyramids," or other patterns identical to the master, on the substrate.

6.2. Vapor-Phase Monomers. Several previous researchers have conducted SI-ROMP with monomers in the vapor phase such as dicyclopentadiene (DCPD), cyclohexadiene (CHD), cyclooctadiene (COD), or cyclododecene (CD) [16, 18]. These monomers are usually challenging for SI-ROMP as they have comparatively smaller ring strains. Therefore, the driving force of the polymerization reaction is weaker, and the competitive effect of chain transfer reactions becomes more significant. By using vapor-phase monomers, the rate of chain transfer is minimized due to reduced chain mobility at the vapor-solid interface $[86,89]$, so the polymerization can proceed in the forward direction at a faster rate. Lerum et al. reported that the critical strain energy required to render the polymerization reaction thermodynamically feasible using vapor-phase monomers is only $2.2 \mathrm{kcal} / \mathrm{mol}$, while the required strain energy of solution-phase monomers is estimated to be $13.3 \mathrm{kcal} / \mathrm{mol}$ [18].

6.3. Synthesis of Block Copolymers. Due to the living nature of ROMP, block copolymer brushes could be synthesized by successively exposing the substrate to different monomers $[22,29,90]$. As demonstrated in the research of Kim et al., through IR spectroscopy analyses, the copolymer demonstrates characteristics of polymers of both monomers, while XPS data in the perpendicular direction of the surface is consistent with the latter monomer [29]. This proved the formation of block copolymer brushes, with the layer of the latter monomer covering that of the former monomer.

6.4. Cross-Linking of Polymer Brushes. Cross-linking of polymer brushes has been reported to improve the stability of polymer films $[35,45]$. In a previous study, it has been found that the thickness of the polynorbornene film decreases under rinsing with dichloromethane solvent. To reduce this effect, Fursule et al. utilized a monomer with two norbornenyl groups linked by a PEG (polyethylene glycol) chain 


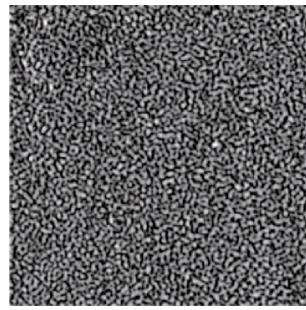

(a)

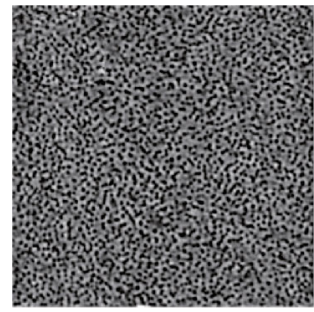

(c)

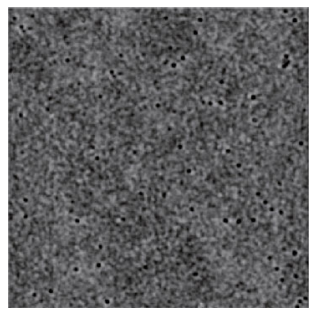

(e)

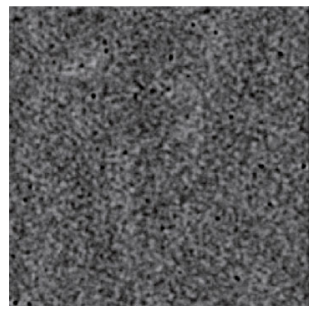

(g)

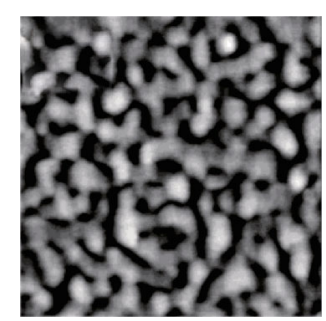

(b)

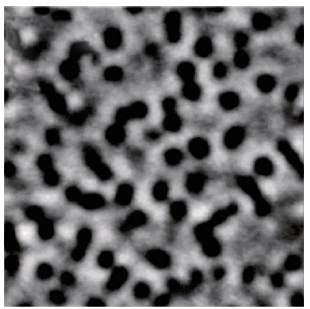

(d)

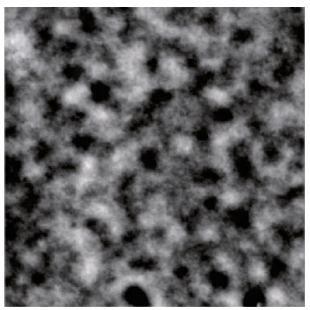

(f)

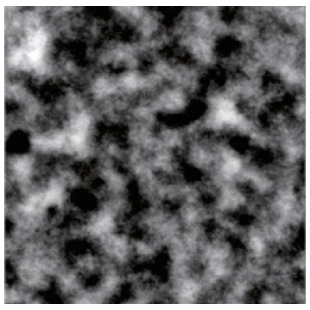

(h)

Figure 7: The AFM images taken at different times of polymerization: (a, b) 30 minutes, (c, d) 1 hour, (e, f) 2 hours, and (g, h) 4 hours, in the work of Harada et al. [33], where images in the bottom row are high-resolution scans $(1 \mu \mathrm{m} \times 1 \mu \mathrm{m})$ of those in the top row $(5 \mu \mathrm{m} \times 5 \mu \mathrm{m})$. Figure reprinted with permission from [33]. Copyright @ 2003 American Chemical Society.

(Figure 8(a)), which was mixed with the olefin monomer during polymerization [35]. The resulting polymer films showed improved stabilities. In their research, it was reported that the film loss after 10 rinses with dichloromethane reduced from approximately $73 \%$ down to only $28 \%$. A similar approach was adopted by Pattison et al. [45], in which a macro-cross-linker containing spaced-out norbornene groups was used to prepare cross-linked polynorbornene films (Figure 8(b)).

6.5. Postpolymerization Functionalizations. Postpolymerization functionalizations have also been adopted to tune the properties of the surface-tethered polymers. For ROMP polymers, the olefin groups in the backbone are often used for further functionalization, one of which is sulfonation [34, 91]. According to the method reported by Berron et al. in 2008, the polymer film generated by SI-ROMP was exposed to a dichloromethane solution of acetyl sulfate, which sulfonated the olefin groups in the polymer chains. As a large portion of reactive olefin groups on the polymer is removed, sulfonation yields a more chemically stable polymer film. Another example is the epoxidation. The olefin groups can undergo epoxidation by treating the polymer film with meta-chloroperoxybenzoic acid (mCPBA) [23, 39]. In addition, metal ions can also be incorporated into polymer films by first treating poly(norbornenyl dicarbonyl chloride) generated by SI-ROMP with hydroxylamine $\left(\mathrm{NH}_{2} \mathrm{OH}\right)$ and then exposing the polymer film to a solution of transition metal salt (for instance, $\mathrm{Fe}^{2+}$ ) [26]. The chelation process is depicted in Figure 9.

In conclusion, advanced techniques have been employed in SI-ROMP to better control the polymerization process and to give specialized surface-grafted polymer films with novel properties. Soft lithography methods such as $\mu \mathrm{CP}$ and 
<smiles>CC(C)OCCOC(=O)C1C2C=CC1C(C(=O)OC(C)C)C2</smiles>

(a)

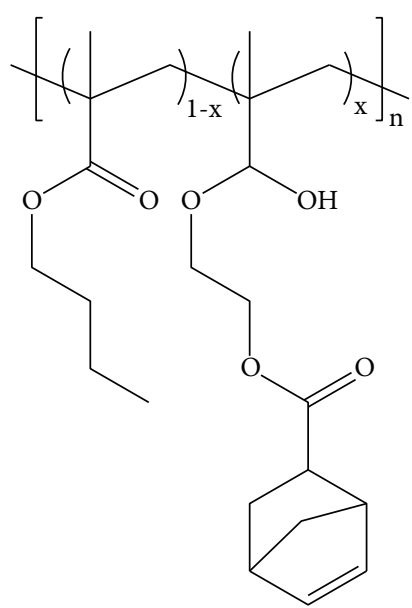

(b)

Figure 8: The cross-linking reagents used in the work of (a) Fursule et al. [35] and (b) Pattison et al. [45]

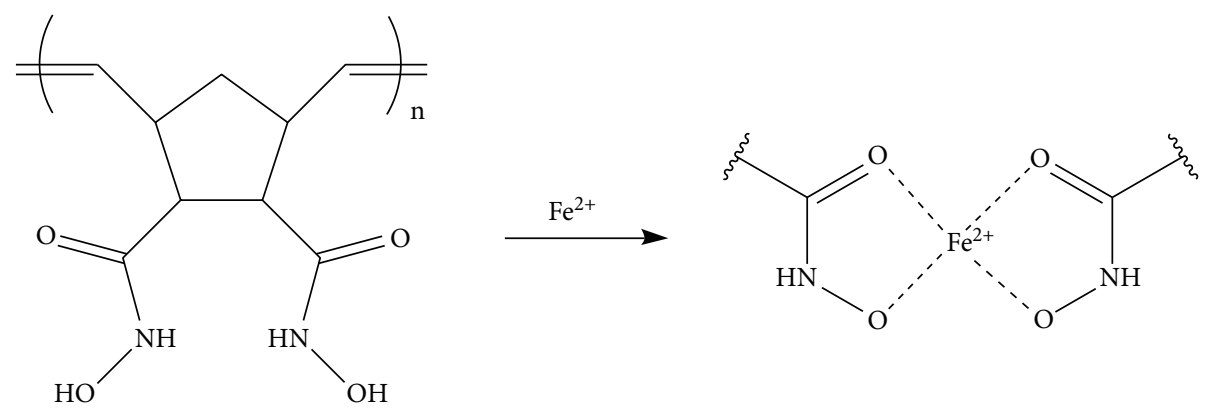

FIGURE 9: The chelation of hydroxylamine-processed poly(norbornenyl dicarbonyl chloride) with a ferrous ion.

$\mu \mathrm{MSIP}$ are used to generate patterned polymer films. Vaporphase monomers reduce the chain-transfer reactions and allow the SI-ROMP of low-strain cyclic olefins. Block copolymerization and cross-linking of polymer chains introduced polymer films with novel architectures. Last but not least, postpolymerization functionalization such as sulfonation and epoxidation modified the physical and chemical properties of the polyolefin film.

\section{Applications}

Coating surfaces with SI-ROMP polymer films have profound applications due to the ability to functionalize surfaces by modifying their physical and chemical properties. In this section, recently reported uses and applications of SIROMP-generated polymer films and the coated surfaces will be discussed.

7.1. Modification of Surface Hydrophilicity. One of the most common applications of polymer coatings is to modify the hydrophilicity of the substrate that the polymer chains are tethered to. In the case of SI-ROMP on cellulose fibers [24], the polynorbornene-coated cellulose fiber sheet became considerably hydrophobic, with advancing contact angles $\left(\theta_{\mathrm{A}}\right)$ being greater than $100^{\circ}$ with water. An ultrahydrophobic surface can have a self-cleaning property as water droplets would simply roll off the surface and carry away any dry con- taminants $[92,93]$. This could protect metal surfaces (such as copper or aluminum) from corrosion by deliquescence of salt particles (such as sodium chloride) in humid air, usually in marine environments [94, 95]. By rendering a surface hydrophobic, SI-ROMP could be used to modify the wettability of the channels in microfluidic devices [96-98] to introduce flow regulations, such as hydrophobic capillary stop valves. Also, previous researches carried out SI-ROMP of fluorinated norbornenes (NBFn) to graft a hydrophobic and oleophobic polymer film $[25,91]$. Surfaces that are neither hydrophilic nor oleophilic are referred to as "ambiguous" and could possess antibiofouling properties due to the weakening of both hydrophilic and hydrophobic interactions [99].

7.2. Electric Devices. SI-ROMP could be adopted to generate polymer dielectric layers used in Field-Effect Transistors (FETs). Rutenberg et al. reported the success of constructions of fully functional FETs using a polymer produced by SIROMP [14]. Compared to traditional inorganic-based FETs, the incorporation of organic polymer materials in FETs is considered desirable due to lower weight, cost, and higher facility of processing [100]. In which case, due to the chemical and electrical compatibility of surface-initiated polymer dielectric layers with other component layers in FETs, SIROMP can compete with other methods such as spin-coating, inkjet printing, and screen printing to generate densely packed organic polymer layers [101]. Furthermore, it was 
demonstrated by Yan et al. that SI-ROMP-generated polymers on $\mathrm{TiO}_{2}$ nanowires could construct an ordered p-n heterojunction, which possessed extensive photoelectric properties and could be applied in inorganic-organic hybrid solar cells [81]. Through SI-ROMP, the nanocrystals are tightly wrapped by polymer chains, and the photoelectric performances are expected to be largely enhanced owing to direct interfacial contact.

7.3. Ion Exchange Media. Sulfonated polyolefins could form charged polymer layers under deprotonation, which could be utilized as ion-exchange media. For instance, acting as a polyelectrolyte, sulfonated polyolefins have applications in fuel cells [34]. In the research of Berron et al., they measured extremely low resistances of sulfonated polyolefin films against proton transfer (approximately $1.6 \Omega \mathrm{cm}^{2}$ ) compared to nonsulfonated polyolefin films (approximately $10^{6.5} \Omega \mathrm{cm}^{2}$ ) in a $0.1 \mathrm{M} \mathrm{H}_{2} \mathrm{SO}_{4}$ aqueous electrolyte solution, simulating the acidic environment inside a fuel cell. Due to this low resistance against proton exchange, it was also suggested that sulfonated polyolefin films could be used in proton transfer membranes [102, 103]. Aside from protons, anion exchange films were also crafted by SI-ROMP [37]. Njoroge et al. synthesized poly(3-[(bicyclo[2.2.1]hept-5-en2-yl)methyl]-1,2-dimethylimidazol-3-ium hexafluorophosphate $\left(\mathrm{p}\left[\mathrm{N}_{1}-\mathrm{dMIm}\right]\left[\mathrm{PF}_{6}\right]\right)$ in 2017 , in which the anionic species $\mathrm{PF}_{6}^{-}$could be easily exchanged with other anions, for instance, $\mathrm{ClO}_{4}{ }^{-}, \mathrm{FSI}^{-}$, and $\mathrm{NTf}_{2}{ }^{-}$, allowing the tunability of surface properties such as ion conduction, color, and wettability.

7.4. Responsive Surfaces. Responsive polymer brushes have also attracted some attention in recent years. Lightresponsive polymer films could be synthesized by adding monomers modified with photochromically active groups such as spiropyran, which would isomerize through a reversible reaction under exposure to light $[20,104]$. Polynorbornene films that undergo morphological changes upon exposure to specific chemicals were also developed. For instance, Sha et al. synthesized a random copolymer of different norbornene monomers on silicon oxide nanoparticles. One monomer contains a triarylmethanol unit, which is responsive to electrophilic organophosphate chemical warfare agents (CWAs) such as sarin or soman [76, 105]. Upon reaction with CWAs, the polymer chains collapse, giving a denser and more protective polymer film, due to stacking between the ionized triarylmethanol units. A similar approach was reported by Deng et al. to generate $\mathrm{pH}-$ sensitive surface copolymer films [106]. After treatment, the polymer films included randomly and sparsely distributed carboxylic acid groups, which allow the stacked chains to straighten and extend outwards in a basic environment, due to electrostatic repulsion between the deprotonated carboxylate groups.

By and large, material applications of SI-ROMP reported to this day could mainly be classified into three categories. Firstly, taking advantage of the hydrophobicity/oleophobicity of SI-ROMP polymer films, microfluidic channels, selfcleaning, corrosion-resistant, and antibiofouling surfaces could be crafted. Secondly, considering the dielectric and photoelectric properties of organic polymer films, SI-ROMP has been incorporated into FETs and inorganic-organic hybrid solar cells. Thirdly, based on the chemical properties and reactivities of polyolefins by SI-ROMP, ion exchange media and stimuli-responsive surfaces are crafted.

\section{Conclusion, Challenges, and Future Opportunities}

Although ROMP reactions and catalysts have been investigated for a long time, SI-ROMP is still a new field with only about 20 years of history. In this review article, it is shown that SI-ROMP is an efficient way of generating polymer brushes on a variety of inorganic or organic substrates. Well-defined catalysts for SI-ROMP have been developed, synthesized, and used, and several techniques can be utilized to modify or improve the properties and architectures of the polymer film. Furthermore, a range of characterization methods for the surface-grafted polymer film generated by SI-ROMP and the material applications of surface-tethered polymer films have been developed.

A challenge that remains for SI-ROMP is its significant chain-transfer reactions due to the proximity of growing polymer chains on the surface, competing with the forward polymerization reaction. This challenge has been shown to be particularly important as it directly affects the polymerization chain termination rate and, hence, the thickness of the resulting polymer films. Although researchers have attempted to reduce chain-transfer reactions by using vapor-phase monomers, quantitative investigations of the chain transfer reactions in SI-ROMP are still needed.

In recent years, more SI-ROMP researches about specific material applications have started to appear, demonstrating the relative maturity of the polymerization technique itself and a shift in focus towards more practical applications. Current researches suggest the possibility of applying SI-ROMP in various kinds of materials, including electronic devices, microfluidics, antibiofouling surfaces, ion exchange media, and responsive surfaces. Compared to other SIP techniques, SI-ROMP has unique advantages such as mild reaction conditions, fast rate of polymer growth, and high tolerance to different functional groups. Furthermore, the diverse reactivity of remaining olefin functionalities on SI-ROMPgenerated polymers opens vast possibilities for postpolymerization functionalizations. Therefore, SI-ROMP provides large potentials and numerous opportunities for surface engineering with functional polymers. Future researches can focus on further expanding the substrate scope of SI-ROMP, developing strategies of postpolymerization functionalization of surface-grafted polymer films, and quantitatively investigating the chain-transfer reactions competing with the polymerization. More importantly, broader applications of SI-ROMP in material science are still waiting to be demonstrated.

\section{Conflicts of Interest}

The author declares that there is no conflict of interest. 


\section{Acknowledgments}

This work acknowledges the generous help and guidance in writing this review article provided by Mr. Qilin He, currently pursuing doctoral studies at the Massachusetts Institute of Technology.

\section{References}

[1] C. W. Bielawski and R. H. Grubbs, "Living ring-opening metathesis polymerization," Progress in Polymer Science, vol. 32, no. 1, pp. 1-29, 2007.

[2] N. Calderon, "Ring-opening polymerization of cycloolefins," Journal of Macromolecular Science, Part C, vol. 7, no. 1, pp. 105-159, 2006.

[3] G. Dall'Asta, "Preparation and properties of polyalkenamers," Rubber Chemistry and Technology, vol. 47, no. 3, pp. 511-596, 1974.

[4] B. M. Novak, W. Risse, and R. H. Grubbs, "The development of well-defined catalysts for ring-opening olefin metathesis polymerizations (romp)," in Polymer Synthesis Oxidation Processes, pp. 47-72, Springer, 1992.

[5] K. J. Ivin and J. C. Mol, Olefin metathesis and metathesis polymerization, Elsevier, 1997.

[6] M. R. Buchmeiser, "Homogeneous metathesis polymerization by well-defined group vi and group viii transitionmetal alkylidenes: fundamentals and applications in the preparation of advanced materials," Chemical Reviews, vol. 100, no. 4, pp. 1565-1604, 2000.

[7] U. Frenzel and O. Nuyken, "Ruthenium-based metathesis initiators: development and use in ring-opening metathesis polymerization," Journal of Polymer Science Part A: Polymer Chemistry, vol. 40, no. 17, pp. 2895-2916, 2002.

[8] S. Sutthasupa, M. Shiotsuki, and F. Sanda, "Recent advances in ring-opening metathesis polymerization, and application to synthesis of functional materials," Polymer Journal, vol. 42, no. 12, pp. 905-915, 2010.

[9] J. Ping, H. Pan, P.-. P. Hou et al., "Solid polymer electrolytes with excellent high-temperature properties based on brush block copolymers having rigid side chains," ACS Applied Materials \& Interfaces, vol. 9, no. 7, pp. 6130-6137, 2017.

[10] D.-P. Song, C. Li, N. S. Colella, X. Lu, J.-H. Lee, and J. J. Watkins, "Thermally tunable metallodielectric photonic crystals from the self-assembly of brush block copolymers and gold nanoparticles," Advanced Optical Materials, vol. 3, no. 9, pp. 1169-1175, 2015.

[11] M. Weck, J. J. Jackiw, R. R. Rossi, P. S. Weiss, and R. H. Grubbs, "Ring-opening metathesis polymerization from surfaces," Journal of the American Chemical Society, vol. 121, no. 16, pp. 4088-4089, 1999.

[12] J. O. Zoppe, N. C. Ataman, P. Mocny, J. Wang, J. Moraes, and H.-A. Klok, "Surface-initiated controlled radical polymerization: state-of-the-art, opportunities, and challenges in surface and interface engineering with polymer brushes," Chemical Reviews, vol. 117, no. 3, pp. 1105-1318, 2017.

[13] R. Advincula, "Polymer brushes by anionic and cationic surface-initiated polymerization (sip)," in Surface-initiated polymerization I, pp. 107-136, Springer, 2006.

[14] I. M. Rutenberg, O. A. Scherman, R. H. Grubbs, W. Jiang, E. Garfunkel, and Z. Bao, "Synthesis of polymer dielectric layers for organic thin film transistors via surface-initiated ring-opening metathesis polymerization," Journal of the American Chemical Society, vol. 126, no. 13, pp. 4062-4063, 2004.

[15] C. A. Escobar, R. R. Harl, K. E. Maxwell, N. N. Mahfuz, B. R. Rogers, and G. K. Jennings, "Amplification of surfaceinitiated ring-opening metathesis polymerization of 5-(perfluoro-n-alkyl) norbornenes by macroinitiation," Langmuir, vol. 29, no. 40, pp. 12560-12571, 2013.

[16] I. Njoroge, P. A. Kempler, X. Deng, S. T. Arnold, and G. K. Jennings, "Surface-initiated ring-opening metathesis polymerization of dicyclopentadiene from the vapor phase," Langmuir, vol. 33, no. 49, pp. 13903-13912, 2017.

[17] G. Jiang, R. Ponnapati, R. Pernites, M. J. Felipe, and R. Advincula, "Surface-initiated ring-opening metathesis polymerization (SI-ROMP): synthesis and electropolymerization of terthiophene-functionalized olefin peripheral dendrons," Macromolecules, vol. 43, no. 24, pp. 10262-10274, 2010 .

[18] M. F. Z. Lerum and W. Chen, "Surface-initiated ring-opening metathesis polymerization in the vapor phase: an efficient method for grafting cyclic olefins with low strain energies," Langmuir, vol. 27, no. 9, pp. 5403-5409, 2011.

[19] B. J. Berron, E. P. Graybill, and G. K. Jennings, "Growth and structure of surface-initiated poly (n-alkylnorbornene) films," Langmuir, vol. 23, no. 23, pp. 11651-11655, 2007.

[20] S. Samanta and J. Locklin, "Formation of photochromic spiropyran polymer brushes via surface-initiated, ring-opening metathesis polymerization: reversible photocontrol of wetting behavior and solvent dependent morphology changes," Langmuir, vol. 24, no. 17, pp. 9558-9565, 2008.

[21] Q. Ye, X. Wang, S. Li, and F. Zhou, "Surface-initiated ringopening metathesis polymerization of pentadecafluorooctyl5-norbornene-2-carboxylate from variable substrates modified with sticky biomimic initiator," Macromolecules, vol. 43, no. 13, pp. 5554-5560, 2010.

[22] B. Kong, J. K. Lee, and I. S. Choi, "Surface-initiated, ringopening metathesis polymerization: formation of diblock copolymer brushes and solvent-dependent morphological changes," Langmuir, vol. 23, no. 12, pp. 6761-6765, 2007.

[23] Q. Zhang, Q.-L. Li, S. Xiang et al., "Covalent modification of graphene oxide with polynorbornene by surface-initiated ring-opening metathesis polymerization," Polymer, vol. 55, no. 23, pp. 6044-6050, 2014.

[24] L. Carlsson, E. Malmström, and A. Carlmark, "Surface-initiated ring-opening metathesis polymerisation from cellulose fibres," Polymer Chemistry, vol. 3, no. 3, pp. 727-733, 2012.

[25] C. J. Faulkner, P. Andrew Payne, and G. K. Jennings, "Surface-initiated ring-opening metathesis polymerization of 5(perfluorohexyl)norbornene on carbon paper electrodes," Journal of Colloid and Interface Science, vol. 351, no. 1, pp. 248-253, 2010.

[26] X. Deng, L. Prozorovska, and G. K. Jennings, "Metal chelating polymer thin films by surface-initiated romp and modification," The Journal of Physical Chemistry C, vol. 123, no. 38, pp. 23511-23519, 2019.

[27] M. R. Buchmeiser, F. Sinner, M. Mupa, and K. Wurst, "Ringopening metathesis polymerization for the preparation of surface-grafted polymer supports," Macromolecules, vol. 33, no. 1, pp. 32-39, 2000

[28] X. Liu, S. Guo, and C. A. Mirkin, "Surface and site-specific ring-opening metathesis polymerization initiated by dip- 
pen nanolithography," Angewandte Chemie, vol. 115, no. 39, pp. 4933-4937, 2003.

[29] N. Y. Kim, N. L. Jeon, I. S. Choi et al., "Surface-initiated ringopening metathesis polymerization on $\mathrm{Si} / \mathrm{SiO}_{2}$," Macromolecules, vol. 33, no. 8, pp. 2793-2795, 2000.

[30] N. L. Jeon, I. S. Choi, G. M. Whitesides et al., "Patterned polymer growth on silicon surfaces using microcontact printing and surface-initiated polymerization," Applied Physics Letters, vol. 75, no. 26, pp. 4201-4203, 1999.

[31] F. Cesano and D. Scarano, "Dispersion of carbon-based materials (CNTs, graphene) in polymer matrices," in Carbon for Sensing Devices, pp. 43-75, Springer, 2015.

[32] S. H. Kalluru and E. W. Cochran, "Synthesis of polyolefin/layered silicate nanocomposites via surface-initiated ringopening metathesis polymerization," Macromolecules, vol. 46, no. 23, pp. 9324-9332, 2013.

[33] Y. Harada, G. S. Girolami, and R. G. Nuzzo, "Catalytic amplification of patterning via surface-confined ring-opening metathesis polymerization on mixed primer layers formed by contact printing," Langmuir, vol. 19, no. 12, pp. 51045114, 2003.

[34] B. J. Berron, P. A. Payne, and G. K. Jennings, "Sulfonation of surface-initiated polynorbornene films," Industrial \& Engineering Chemistry Research, vol. 47, no. 20, pp. 7707-7714, 2008.

[35] I. A. Fursule, A. Abtahi, C. B. Watkins Jr., K. R. Graham, and B. J. Berron, "In situ crosslinking of surface-initiated ring opening metathesis polymerization of polynorbornene for improved stability," Journal of Colloid and Interface Science, vol. 510, pp. 86-94, 2018.

[36] T. Zhu, M. A. Rahman, and B. C. Benicewicz, "Synthesis of well-defined polyolefin grafted $\mathrm{SiO} 2 \mathrm{Nanoparticles}$ with molecular weight and graft density control," ACS Macro Letters, vol. 9, no. 9, pp. 1255-1260, 2020.

[37] I. Njoroge, M. W. Matson, and G. K. Jennings, "Dynamic anion-adaptive poly (ionic liquid) films via surface-initiated ring-opening metathesis polymerization," The Journal of Physical Chemistry C, vol. 121, no. 37, pp. 20323-20334, 2017.

[38] S.-T. Chiu, H.-Y. Chiang, Y.-J. Lin et al., "Self-assembly and ring-opening metathesis polymerization of cyclic conjugated molecules on highly ordered pyrolytic graphite," Chemical Communications, vol. 54, no. 44, pp. 5546-5549, 2018.

[39] Z. Song, X. Su, K. Huang, H. Lin, F. Liu, and J. Tang, "Epoxidation of surface-bound polynorbornene films on silicon: preventing degradation via solvent effect," Polymer, vol. 52, no. 20, pp. 4456-4462, 2011.

[40] E. Cao, L. Pichavant, E. Prouzet, and V. Héroguez, "The formation and study of poly (ethylene oxide)-poly (norbornene) block-copolymers on the surface of titanium-dioxide particles: a novel approach towards application of si-romp to larger surface modification," Polymer Chemistry, vol. 7, no. 15, pp. 2751-2758, 2016.

[41] H. A. Haque, S. Kakehi, M. Hara, S. Nagano, and T. Seki, "High-density liquid-crystalline azobenzene polymer brush attained by surface-initiated ring-opening metathesis polymerization," Langmuir, vol. 29, no. 25, pp. 7571-7575, 2013.

[42] Q. Ye, B. He, Y. Zhang, J. Zhang, S. Liu, and F. Zhou, "Grafting robust thick zwitterionic polymer brushes via subsurfaceinitiated ring-opening metathesis polymerization for antimicrobial and anti-biofouling," ACS Applied Materials \& Interfaces, vol. 11, no. 42, pp. 39171-39178, 2019.
[43] R. H. Grubbs and R. Weitekamp, "Birefringent polymer brush structures formed by surface initiated ring-opening metathesis polymerization," 2016, US Patent 9,234,985.

[44] F. Vatansever and M. R. Hamblin, "Surface-initiated ringopening metathesis polymerization (SI-ROMP) to attach a tethered organic corona onto CdSE/ZnS core/shell quantum dots," Journal of Nanoparticle Research, vol. 18, no. 10, p. 302, 2016.

[45] T. G. Pattison, A. Spanu, A. M. Friz, Q. Fu, R. D. Miller, and G. G. Qiao, "Growing patterned, cross-linked nanoscale polymer films from organic and inorganic surfaces using ringopening metathesis polymerization," ACS Applied Materials \& Interfaces, vol. 12, no. 3, pp. 4041-4051, 2019.

[46] S. A. Pendergraph, G. Klein, M. K. G. Johansson, and A. Carlmark, "Mild and rapid surface initiated ring-opening polymerisation of trimethylene carbonate from cellulose," RSC Advances, vol. 4, no. 40, pp. 20737-20743, 2014.

[47] J. Pribyl, B. Benicewicz, M. Bell et al., "Polyethylene grafted silica nanoparticles prepared via surface-initiated ROMP," ACS Macro Letters, vol. 8, no. 3, pp. 228-232, 2019.

[48] M. S. Yavuz and G. A. Sotzing, "Surface grafting of electrochemically crosslinked poly(3,4-ethylenedioxythiophene) (PEDOT) brushes via surface-initiated ring- opening metathesis polymerization," European Polymer Journal, vol. 48, no. 4, pp. 875-880, 2012.

[49] R. H. Grubbs, D. D. Carr, C. Hoppin, and P. L. Burk, "Consideration of the mechanism of the metal catalyzed olefin metathesis reaction," Journal of the American Chemical Society, vol. 98, no. 12, pp. 3478-3483, 1976.

[50] O. Nuyken and S. D. Pask, "Ring-opening polymerization-an introductory review," Polymers, vol. 5, no. 2, pp. 361-403, 2013.

[51] I. Choinopoulos, “Grubbs' and Schrock's catalysts, ring opening metathesis polymerization and molecular brushes-synthesis, characterization, properties and applications," Polymers, vol. 11, no. 2, p. 298, 2019.

[52] P. Jean-Louis Hérisson Y. Chauvin et al., Makromolekulare Chemie Rapid communications, vol. 141, no. 1, pp. 161-176, 1971.

[53] T. M. Trnka and R. H. Grubbs, "The development of $\mathrm{L}_{2} \mathrm{X}_{2} \mathrm{RuCHR}$ olefin metathesis catalysts: an organometallic success story," Accounts of Chemical Research, vol. 34, no. 1, pp. 18-29, 2001.

[54] E. O. Fischer and A. Maasböl, "Zur frage eines wolfram-carbonyl-carben-komplexes," Angewandte Chemie, vol. 76, no. 14, pp. 645-645, 1964.

[55] E. O. Fischer and A. Maasböl, "On the existence of a tungsten carbonyl carbene complex," Angewandte Chemie International Edition in English, vol. 3, no. 8, pp. 580-581, 1964.

[56] C. P. Casey and T. J. Burkhardt, "(Diphenylcarbene) pentacarbonyltungsten (0)," Journal of the American Chemical Society, vol. 95, no. 17, pp. 5833-5834, 1973.

[57] C. P. Casey and T. J. Burkhardt, "Reactions of (diphenylcarbene)pentacarbonyltungsten $(0)$ with alkenes. Role of metalcarbene complexes in cyclopropanation and olefin metathesis reactions," Journal of the American Chemical Society, vol. 96, no. 25, pp. 7808-7809, 1974.

[58] C. P. Casey, H. E. Tuinstra, and M. C. Saeman, "Reactions of (CO)5WC(Tol)2 with alkenes. A model for structural selectivity in the olefin metathesis reaction," Journal of the American Chemical Society, vol. 98, no. 2, pp. 608-609, 1976. 
[59] T. J. Katz, S. J. Lee, and N. Acton, "Stereospecific polymerizations of cycloalkenes induced by a metal-carbene," Tetrahedron Letters, vol. 17, no. 47, pp. 4247-4250, 1976.

[60] T. J. Katz and N. Acton, "Metatheses induced by (phenylmethoxycarbene)pentacarbonyltungsten," Tetrahedron Letters, vol. 17, no. 47, pp. 4251-4254, 1976.

[61] J. Kress, J. A. Osborn, R. M. E. Greene, K. J. Ivin, and J. J. Rooney, "First direct observation of the simultaneous presence and of the interconversion of chain-propagating metalcarbene and metallacyclobutane complexes in a catalytic olefin metathesis reaction: the ring-opening polymerization of norbornene," Journal of the American Chemical Society, vol. 109, no. 3, pp. 899-901, 1987.

[62] J. Kress, A. Aguero, and J. A. Osborn, "Recent advances in the chemistry of tungsten-carbene complexes," Journal of Molecular Catalysis, vol. 36, no. 1-2, pp. 1-12, 1986.

[63] C. J. Schaverien, J. C. Dewan, and R. R. Schrock, "Multiple metal-carbon bonds. 43. Well-characterized, highly active, Lewis acid free olefin metathesis catalysts," Journal of the American Chemical Society, vol. 108, no. 10, pp. 2771-2773, 1986.

[64] J. H. Wengrovius and R. R. Schrock, "Synthesis and characterization of tungsten oxo neopentylidene complexes," Organometallics, vol. 1, no. 1, pp. 148-155, 1982.

[65] L. L. Blosch, K. Abboud, and J. M. Boncella, "Synthesis of an air-stable, moisture-stable, and thermally stable tungsten(VI) oxo alkylidene complex. Precursor to an air- and moisturestable romp catalyst," Journal of the American Chemical Society, vol. 113, no. 18, pp. 7066-7068, 1991.

[66] R. H. Grubbs and W. Tumas, "Polymer synthesis and organotransition metal chemistry," Science, vol. 243, no. 4893, pp. 907-915, 1989.

[67] K. C. Wallace, A. H. Liu, J. C. Dewan, and R. R. Schrock, "Preparation and reactions of tantalum alkylidene complexes containing bulky phenoxide or thiolate ligands. Controlling ring-opening metathesis polymerization activity and mechanism through choice of anionic ligand," Journal of the American Chemical Society, vol. 110, no. 15, pp. 4964-4977, 1988.

[68] R. H. Grubbs, "The development of functional group tolerant romp catalysts," Journal of Macromolecular Science, Part A, vol. 31, no. 11, pp. 1829-1933, 1994.

[69] S. B. T. Nguyen, L. K. Johnson, R. H. Grubbs, and J. W. Ziller, "Ring-opening metathesis polymerization (romp) of norbornene by a group viii carbene complex in protic media," Journal of the American Chemical Society, vol. 114, no. 10, pp. 3974-3975, 1992.

[70] P. Schwab, M. B. France, J. W. Ziller, and R. H. Grubbs, “A series of well-defined metathesis catalysts-synthesis of [rucl2 $(=\mathrm{chr})(\mathrm{pr} 3) 2]$ and its reactions," Angewandte Chemie International Edition in English, vol. 34, no. 18, pp. 2039-2041, 1995.

[71] P. Schwab, R. H. Grubbs, and J. W. Ziller, "Synthesis and applications of $\mathrm{RuCl}_{2}\left(\mathrm{CHR}^{\prime}\right)\left(\mathrm{PR}_{3}\right)_{2}$ : the influence of the alkylidene moiety on metathesis activity," Journal of the American Chemical Society, vol. 118, no. 1, pp. 100-110, 1996.

[72] A. Leitgeb, J. Wappel, and C. Slugovc, "The romp toolbox upgraded,” Polymer, vol. 51, no. 14, pp. 2927-2946, 2010.

[73] C. A. Escobar, T. J. Cooksey, M. P. Spellings, and G. K. Jennings, "Micromolding surface-initiated polymerization: a versatile route for fabrication of coatings with microscale surface features of tunable height," Advanced Materials Interfaces, vol. 1, no. 7, article 1400055, 2014.
[74] H. Häkkinen, "The gold-sulfur interface at the nanoscale," Nature Chemistry, vol. 4, no. 6, pp. 443-455, 2012.

[75] J. A. LaNasa and R. J. Hickey, "Surface-initiated ring-opening metathesis polymerization: a method for synthesizing polymer-functionalized nanoparticles exhibiting semicrystalline properties and diverse macromolecular architectures," Macromolecules, vol. 53, no. 19, pp. 8216-8232, 2020.

[76] S.-C. Sha, R. Zhu, M. B. Herbert, J. A. Kalow, and T. M. Swager, "Chemical warfare simulant-responsive polymer nanocomposites: synthesis and evaluation," Journal of Polymer Science Part A: Polymer Chemistry, vol. 55, no. 18, pp. 3034-3040, 2017.

[77] K. R. Finnie, R. Haasch, and R. G. Nuzzo, "Formation and patterning of self-assembled monolayers derived from longchain organosilicon amphiphiles and their use as templates in materials microfabrication," Langmuir, vol. 16, no. 17, pp. 6968-6976, 2000.

[78] D. L. Allara, A. N. Parikh, and F. Rondelez, "Evidence for a unique chain organization in long chain silane monolayers deposited on two widely different solid substrates," Langmuir, vol. 11, no. 7, pp. 2357-2360, 1995.

[79] A. N. Parikh, D. L. Allara, I. B. Azouz, and F. Rondelez, “An intrinsic relationship between molecular structure in selfassembled n-alkylsiloxane monolayers and deposition temperature," The Journal of Physical Chemistry, vol. 98, no. 31, pp. 7577-7590, 1994.

[80] A. Juang, O. A. Scherman, R. H. Grubbs, and N. S. Lewis, "Formation of covalently attached polymer overlayers on $\mathrm{Si}$ (111) surfaces using ring-opening metathesis polymerization methods," Langmuir, vol. 17, no. 5, pp. 1321-1323, 2001.

[81] J. Yan, Q. Ye, X. Han, and F. Zhou, "Step-by-step build-up of ordered $\mathrm{p}-\mathrm{n}$ heterojunctions at nanoscale for efficient light harvesting," RSC Advances, vol. 3, no. 1, pp. 166-171, 2013.

[82] D. Finkelstein-Shapiro, S. K. Davidowski, P. B. Lee et al., "Direct evidence of chelated geometry of catechol on $\mathrm{TiO}_{2}$ by a combined solid-state NMR and DFT study," The Journal of Physical Chemistry C, vol. 120, no. 41, pp. 23625-23630, 2016.

[83] R. Rodríguez, M. A. Blesa, and A. E. Regazzoni, "Surface complexation at the $\mathrm{TiO}_{2}$ (anatase)/aqueous solution interface: chemisorption of catechol," Journal of Colloid and Interface Science, vol. 177, no. 1, pp. 122-131, 1996.

[84] F. Gómez, R. Chen, D. Wang, R. Waymouth, and H. Dai, "Ring opening metathesis polymerization on non-covalently functionalized single-walled carbon nanotubes," Chemical Communications (Cambridge, England), vol. 9, no. 2, pp. 190-191, 2003.

[85] C. Detrembleur, C. Jérôme, M. Claes, P. Louette, and R. Jérôme, "Combination of electrografting and ringopening metathesis polymerization: an efficient way to prepare polynorbornene brushes on conducting substrates," Angewandte Chemie - International Edition, vol. 40, no. 7, pp. 1268-1271, 2001.

[86] J. Feng, S. S. Stoddart, K. A. Weerakoon, and W. Chen, “An efficient approach to surface-initiated ring-opening metathesis polymerization of cyclooctadiene," Langmuir, vol. 23, no. 3, pp. 1004-1006, 2007.

[87] Y. Xia and G. M. Whitesides, "Soft lithography," Annual Review of Materials Science, vol. 28, no. 1, pp. 153-184, 1998.

[88] C. A. Escobar, M. P. Spellings, T. J. Cooksey, and G. K. Jennings, "Reproducing superhydrophobic leaves as coatings 
by micromolding surface-initiated polymerization," Macromolecular Rapid Communications, vol. 35, no. 22, pp. 19371942, 2014.

[89] D. Fu, L. T. Weng, B. Du, O. K. C. Tsui, and B. Xu, "Solventless polymerization at the gas-solid interface to form polymeric thin films," Advanced Materials, vol. 14, no. 5, pp. 339-343, 2002.

[90] K. J. Watson, J. Zhu, S. B. T. Nguyen, and C. A. Mirkin, "Hybrid nanoparticles with block copolymer shell structures," Journal of the American Chemical Society, vol. 121, no. 2, pp. 462-463, 1999.

[91] C. A. Escobar, A. R. Zulkifli, C. J. Faulkner, A. Trzeciak, and G. K. Jennings, "Composite fluorocarbon membranes by surface-initiated polymerization from nanoporous goldcoated alumina," ACS Applied Materials \& Interfaces, vol. 4, no. 2, pp. 906-915, 2012.

[92] R. Blossey, "Self-cleaning surfaces - virtual realities," Nature Materials, vol. 2, no. 5, pp. 301-306, 2003.

[93] J. Peng, X. Zhao, W. Wang, and X. Gong, "Durable selfcleaning surfaces with superhydrophobic and highly oleophobic properties," Langmuir, vol. 35, no. 25, pp. 84048412, 2019.

[94] Z. Lu, P. Wang, and D. Zhang, "Super-hydrophobic film fabricated on aluminium surface as a barrier to atmospheric corrosion in a marine environment," Corrosion Science, vol. 91, pp. 287-296, 2015.

[95] P. Wang, D. Zhang, and Z. Lu, "Advantage of superhydrophobic surface as a barrier against atmospheric corrosion induced by salt deliquescence," Corrosion Science, vol. 90, pp. 23-32, 2015.

[96] B. Zhao, J. S. Moore, and D. J. Beebe, "Surface-directed liquid flow inside microchannels," Science, vol. 291, no. 5506, pp. 1023-1026, 2001.

[97] A. Olanrewaju, M. Beaugrand, M. Yafia, and D. Juncker, "Capillary microfluidics in microchannels: from microfluidic networks to capillaric circuits," Lab on a Chip, vol. 18, no. 16, pp. 2323-2347, 2018.

[98] C. Li, M. Boban, S. A. Snyder et al., "Paper-based surfaces with extreme wettabilities for novel, open-channel microfluidic devices," Advanced Functional Materials, vol. 26, no. 33, pp. 6121-6131, 2016.

[99] Q. Ye, W. Zhao, W. Yang, X. Pei, and F. Zhou, "Grafting binary peg and fluoropolymer brushes from mix-biomimic initiator as "ambiguous" surfaces for antibiofouling," Macromolecular Chemistry and Physics, vol. 218, no. 11, article 1700085, 2017.

[100] I. M. Rutenberg, Functionalized polymers and surfaces via ring-opening metathesis polymerization, $\mathrm{PhD}$ thesis, California Institute of Technology, 2005.

[101] R. P. Ortiz, A. Facchetti, and T. J. Marks, "High-k organic, inorganic, and hybrid dielectrics for low-voltage organic field-effect transistors," Chemical reviews, vol. 110, no. 1, pp. 205-239, 2010.

[102] J.-C. Daigle, V. Dube-Savoie, A. C. Tavares, and J. P. Claverie, "Copolymers of ethylene and sulfonated norbornene for proton exchange membranes," Journal of Polymer Science Part A: Polymer Chemistry, vol. 51, no. 12, pp. 2669-2676, 2013.

[103] L.-K. Chen, C.-S. Wu, M.-C. Chen et al., "Cross-linked norbornene sulfonated poly(ether ketone)s for proton exchange membrane," Journal of Membrane Science, vol. 361, no. 1-2, pp. 143-153, 2010.
[104] F. Krohm, J. Kind, R. Savka et al., "Photochromic spiropyranand spirooxazine-homopolymers in mesoporous thin films by surface initiated romp," Journal of Materials Chemistry C, vol. 4, no. 18, pp. 4067-4076, 2016.

[105] Y. Li, C. Chen, E. R. Meshot et al., "Autonomously responsive membranes for chemical warfare protection," Advanced Functional Materials, vol. 30, no. 25, article 2000258, 2020.

[106] X. Deng, J. L. Livingston, N. J. Spear, and G. K. Jennings, "phresponsive copolymer films prepared by surface-initiated polymerization and simple modification," Langmuir, vol. 36 , no. 3, pp. 715-722, 2020. 